\title{
Acupoint Stimulation for Postoperative Ileus Following Gastrointestinal Surgery: A Systematic Review and Meta- Analysis of Randomized Controlled Trials
}

\begin{abstract}
Introduction: Postoperative ileus is a common complication of gastrointestinal surgery, which leads to unsatisfactory outcomes with current therapies. In this review, we examined whether acupoint stimulation after gastrointestinal surgery can help hasten postoperative recovery of the digestive system.

Methods: A literature search for relevant studies (published as of April 2017) was conducted across eight biomedical databases. Randomized controlled trials (RCTs) which compared acupoint stimulation with placebo, no treatment, sham acupuncture, or standard care, in adults with postoperative ileus were eligible for inclusion. Trials which compared a combination of acupoint stimulation and standard care with standard care were also included. The Cochrane risk of bias was used to evaluate study quality. Outcomes were summarized using risk ratio (RR) and mean difference (MD) for binary and continuous variables, respectively.

Results: Fourteen RCTs (combined $n=1299$ ) that investigated the role of acupoint stimulation in postoperative ileus after cholecystectomy or colorectal cancer (both open and laparoscopic surgery) were identified and included Chinese and English publications. Most of the trials were found to have a high risk of bias. Results of metaanalysis showed that treatment with acupuncture, moxibustion, electroacupuncture, auriculotherapy, and acupoint injection plus standard care was associated with shorter time to passage of first flatus as compared to that with standard care alone. Acupuncture plus standard care was associated with shorter time to first defecation as compared to that with standard care alone.

Conclusions: There is a paucity of high-quality evidence to recommend the use of acupoint stimulation for treatment of postoperative ileus. Randomized trials with adequate sample size, appropriate blinding and rigorous randomization methods should be undertaken to compare acupuncture with both sham and no acupuncture to generate high-quality evidence on this treatment.
\end{abstract}

Keywords: Acupoint stimulation; Postoperative ileus; Systematic review; Randomized controlled trial

\begin{tabular}{|c|}
\hline Review Article \\
\hline Volume 9 Issue 4 - 2017 \\
\hline \multirow{2}{*}{$\begin{array}{l}\text { Ling-shu Wang }{ }^{1 *} \text {, Guannan } \mathrm{Li}^{2} \text {, Xuetong } \mathrm{Gu}^{2} \text {, } \\
\text { Jing } \mathrm{Li}^{2} \text {, and Guang Yang } \\
\text { 'Department of Rehabilitation, Heilongjiang University of } \\
\text { Chinese Medicine, China }\end{array}$} \\
\hline \\
\hline $\begin{array}{l}\text { 'Graduate student, Heilongjiang University of Chinese } \\
\text { Medicine, China }\end{array}$ \\
\hline $\begin{array}{l}{ }^{3} \text { Gynaecology and Obstetrics, Heilongjiang University of } \\
\text { Chinese Medicine, Harbin 150040, China }\end{array}$ \\
\hline $\begin{array}{l}\text { *Corresponding author: Ling-shu Wang, Department } \\
\text { of Rehabilitation, First Affiliated Hospital of Heilongjiang } \\
\text { University of Chinese Medicine, Harbin 150040, China, Tel: } \\
086 \text { 15845008592; Email: wanglingshu2013@163.com }\end{array}$ \\
\hline $\begin{array}{l}\text { Received: October 28, } 2017 \text { | Published: November 20, } \\
2017\end{array}$ \\
\hline
\end{tabular}

Abbreviations: CENTRAL: Cochrane Central Register of Controlled Trials; CINAHL: Dhina Network Knowledge Infrastructure; TND: Time to Return to Normal Diet; CI: Confidence Intervals; Rrs: Risk Ratios; TFD: Time To First Defecation

\section{Introduction}

Postoperative ileus is a type of bowel dysmotility that may occur after surgery. It is a particularly common occurrence after abdominal surgery and is characterized by bloating due to accumulation of fluid and flatus in the bowel, pain, nausea, vomiting, intolerance to solid food, and delayed passage of flatus and formed stool [1]. The incidence of postoperative ileus among patients who underwent colectomy in United States in the year 2004 was $17.4 \%$ [2]. The etiopathogenesis of postoperative ileus is not completely understood; however, surgical manipulation, inflammatory response, and inhibitory neural reflexes are believed to be involved in its causation [3-5]. Postoperative ileus accounts for a considerable morbidity and economic burden and has a detrimental effect on patient satisfaction [6-7]. Acupuncture and moxibustion are traditional Chinese medical modalities that have been in use over the past 2000 years. Acupuncture involves piercing of meridian points (acupoints) on the body with needles for therapeutic purposes. Moxibustion involves the application of smoldering moxa cones or sticks directly or indirectly on acupoints. With advances in acupuncture techniques, other methods for therapeutic stimulation of acupoints on the basis of meridian theory have emerged, including auriculotherapy (puncture of certain reactive spots on the auricle), electroacupuncture (EA; a combination of needling and electrostimulation), acupoint injection (AI; injection of certain Chinese and/or Western pharmaceutical agents into acupoints), acupressure (application of pressure over acupoints instead of needles), and catgut embedment at the acupoints (CE; implantation of chromic catgut into acupoints for continuous stimulation). 
Both animal experiments and clinical studies have shown that acupuncture can induce gastrointestinal transit after abdominal surgery and normalize gastrointestinal function [8-11]. Moreover, EA has been found to promote colonic motility and prevent formation of postoperative intra-abdominal adhesions [12,13]. Moreover, EA stimulation of acupoints was shown to enhance peristalsis after surgery [14,15], and acupuncture was shown to alleviate intra-abdominal adhesions, accelerate postoperative recovery of mitochondrial and rough endoplasmic reticulum function in the intestinal cells, and to increase the small intestinal transit rate in rats [16-18]. To our knowledge, the currently available evidence pertaining to the effects of acupoint stimulation on postoperative ileus has not been systematically appraised. In this review, we sought to examine whether acupoint stimulation can reduce the duration of postoperative ileus in patients who have undergone open or laparoscopic gastrointestinal surgery.

\section{Methods}

\section{Search strategy}

A literature search for relevant studies was conducted on the following online biomedical databases: the Cochrane Central Register of Controlled Trials (CENTRAL); MEDLINE; EMBASE; CINAHL; China Network Knowledge Infrastructure; Wan Fang Database; VIP Database for Chinese Technical Periodicals; and Chinese Biomedical Database. Studies published as of April 2017 were eligible for inclusion. A combination of the following key words were used for the literature search: "ileus", "postoperative", "acupuncture", "moxibustion", "auriculotherapy", "electroacupuncture", "acupoint injection", "acuppressure", and "catgut embedding at acupoints". Titles and abstracts of all retrieved articles were independently screened by two researchers (XTG and GNL) for eligibility. In the second step, full texts of articles were reviewed against the study-selection criteria. Finally, the reference lists of included studies were manually searched to identify any additional studies. No language restriction was employed in the literature search.

Any disagreements on study inclusion between the two reviewers were resolved by participation of a third reviewer (LSW) who made the final decision independently.

\section{Inclusion criteria}

a. Type of studies: Only randomized controlled trials were included.

b. Types of participants: Adult patients undergoing open or laparoscopic gastrointestinal surgery for ileus or bowel obstruction for the first time, regardless of the setting (emergency or elective surgery). Ileus was considered only if it occurred within 72 hours postoperatively [19].

c. Types of interventions: Acupoint stimulation in the postoperative period was included, irrespective of frequency, operative duration every time, number of points, and treatment sessions. Methods for acupoint stimulation in the intervention groups included: (1) acupuncture; (2) moxibustion; (3) auriculotherapy; (4) electroacupuncture; (5) acupoint injection; (6) acupressure (7) catgut embedding at acupoints.
Control groups in the selected RCTs received the following, regardless of details of treatment: No treatment (NT); Placebo; Sham acupuncture (SA); standard care (SC). In addition, we included acupoint stimulation plus standard care compared against the same standard of care.

d. Type of outcome measures: The primary outcome was time to passage of first flatus (TFF; up to 72 hours, calculated as number of hours after the end of surgery to the first observed passage of flatus). The secondary outcomes were: (1) time to first defecation (TFD; up to 72 hours, calculated as number of hours after the end of surgery to the first observed passage of stool); (2) length of hospital stay (LOS; in days); (3) time to return to normal diet (TND; hours; up to 72 hours); (4) mortality (up to 30 days because of ileus); (5) adverse events related to acupoint stimulation (e.g., pain, hematoma, bleeding).

\section{Data extraction}

From the selected studies, data were independently extracted by two reviewers (XTG and GNL) using a novel data extraction form developed for this review. Two other reviewers (GY and JL) then checked and entered the data into the Review Manager 5 software.

Data pertaining to the following variables related to acupuncture treatment were extracted: type of acupoint stimulation, treatment frequency, treatment duration, length of each treatment session, and number of points used. Other extracted data elements included author details, title of study, year of publication, study design, disease, sample size, treatment, type of control interventions, TFD, TFF, LOS, and complications related to acupoint stimulation.

\section{Assessment of risk of bias}

All studies were independently evaluated for risk of bias by four reviewers (XTG, GNL, JL, and GY). The risk of bias was categorized as low, high, or unclear using the criteria specified in the Cochrane Risk of Bias Tool. Disagreements, if any, among the reviewers were resolved by consensus. Bias with regard to random sequence generation, concealment of allocation, blinding (or masking), incomplete outcome data, selective reporting of outcomes, and other sources of bias were evaluated.

\section{Data analysis}

Statistical analyses were conducted using Review Manager 5. Continuous variables are presented as mean differences (MDs) with $95 \%$ confidence intervals (CI), and dichotomous data as risk ratios (RRs) with 95\% CI. Trials were included in the metaanalysis if they were reasonably homogeneous with regard to study design, participants, interventions, control, and outcome measures.

\section{Results}

\section{Description of studies}

A total of 2688 articles (CENTRAL, 14; MEDLINE, 16; EMBASE, 121; CINAHL, 4; CNKI, 1477; VIP, 376; WanFang, 389; CBM, 291) were retrieved on initial search; of these, 878 records were retained after elimination of duplicates. After screening of titles 
and abstracts, 816 trials were excluded. Full-texts of 62 articles were reviewed, of which 48 studies were excluded. Finally, only 14 studies qualified for inclusion in this review (Figure1).

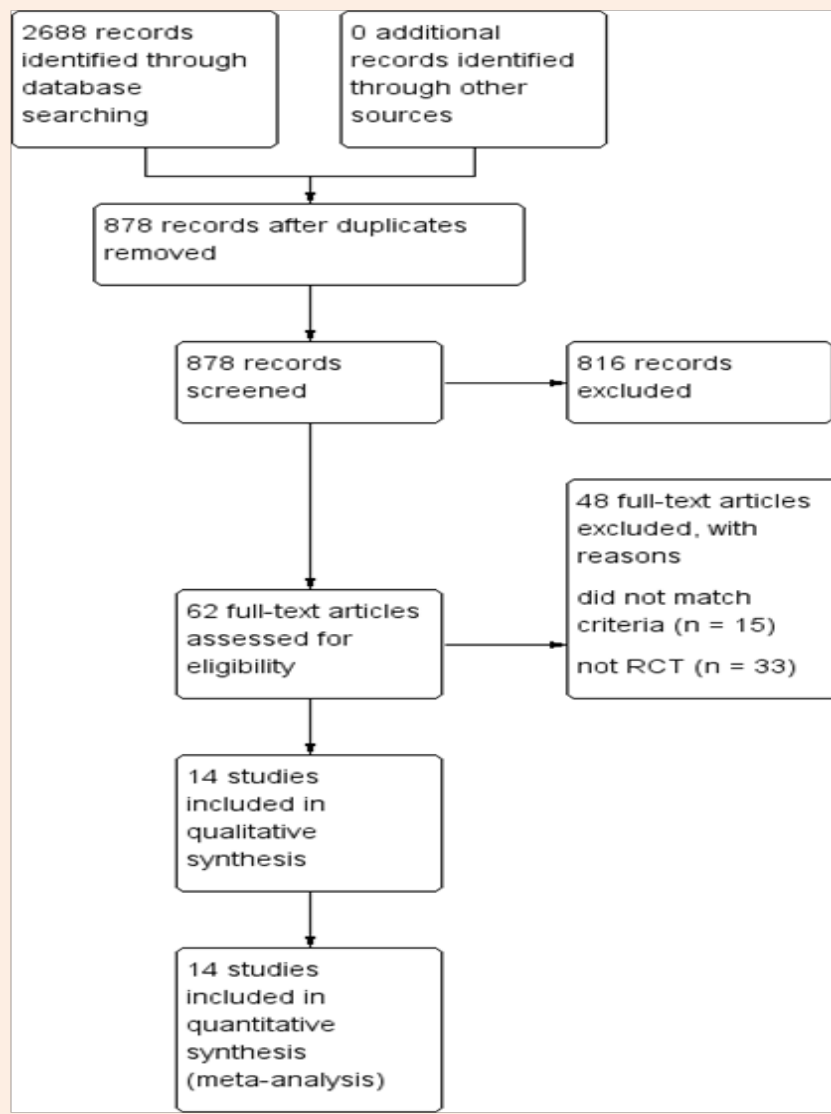

Figure 1: Schematic illustration of literature search and study-selection criteria.

Details of these 14 trials [20-33] are listed in Table 1. Three RCTs incorporated three treatment arms each [24,28,32]. All of the studies had similar design and were conducted after laparoscopic or open surgery for cholecystectomy or colorectal cancer. Twelve articles [20-26,29-33] were published in Chinese language and two $[27,28]$ in English language between 2008 and 2016. All trials were single-center trials.

These 14 trials included a total of 1299 participants. All cases of postoperative ileus were treated in hospital. Gastrointestinal surgery included cholecystectomy and surgery for colorectal cancer. Study sample sizes ranged from 40 to 216 patients; age of patients ranged from 18 to 85 years. Patients were recruited based on clinical presentation of delayed passage of first flatus and defecation, and intolerance to solid food after gastrointestinal surgery. Only one study protocol [28] was reviewed by an institutional review board and reported study participation with informed consent from patients (Table 1).

Acupoint stimulation in treatment groups included acupuncture [27,30], moxibustion [23,24], EA [31,28], auriculotherapy [22,25,33], AI [20,24,32], acupressure [21,32], and CE [29], all of which were accompanied by standard care and compared with the same standard of care in the control group. Only SS Ng et al. [28] compared EA and SA. None of the studies compared acupoint stimulation with placebo or acupoint stimulation with no treatment. There were no reports of mortality or adverse events related to acupoint stimulation in any of the studies included in this review. Detailed information on acupoint stimulation is presented in Table 2 .

\section{Methodological quality}

The 14 studies included in the review were of poor methodological quality (Figure 2). Three studies [25, 26,33] reported using a random number table or coin toss, and were accordingly judged as having a low risk of bias. No information on randomization of subjects was specified for the other 11 studies; these were deemed to have a potentially high risk of bias. Only SS $\mathrm{Ng}$ et al. [28] reported the use of sealed envelopes for treatment allocation and was judged as having a low risk of bias. However, no information on allocation concealment was reported for the remaining 13 trials; these were judged as having an unclear risk of detection bias. Blinding is not possible for acupoint stimulation, especially in China, as most individuals are familiar with acupuncture. However, study by SS Ng et al. [28] had low risk of performance bias as patients were randomized to EA or SA groups and were blinded to the treatment allocation. Qian [29] \& Ng [28] reported blinding of statisticians during statistical analyses; these studies were judged as having a low risk of analysis bias. For the remaining 12 studies, no information related to blinding of participants or personnel was reported; accordingly, these were categorized as having an 'unclear' risk of performance bias. There were no missing outcome data in the 14 studies included in the review, and thereby, there is a low risk of attrition bias. As protocols for 13 studies were not available, the risk of reporting bias was categorized as 'unclear'. Only 1 article reported sample size calculation and was judged to be at a low risk of bias.

\section{Effects of interventions}

\section{Primary outcome}

a. Time to passage of first flatus: All trials reported data on time to passage of first flatus. Results of meta-analysis showed that treatment with acupuncture (MD: $-17.33 \mathrm{~h}, 95 \% \mathrm{CI},-19.40$ to $-15.26 ; 3$ trials, $I^{2}=0 \%$, REM), moxibustion (MD: -10.35 h, $95 \%$ CI, -12.12 to $-8.58 ; 2$ trials, $I^{2}=0 \%$, REM), auriculotherapy (MD: $-12.80 \mathrm{~h}, 95 \% \mathrm{CI},-21.09$ to $-4.5 ; 3$ trials, $I^{2}=97 \%$, REM), EA (MD: $-16.02 \mathrm{~h}, 95 \% \mathrm{CI},-21.55$ to $-10.49 ; 2$ trials, $I^{2}=0 \%$, REM) and AI (MD: $-10.60 \mathrm{~h}, 95 \% \mathrm{CI},-16.13$ to $-5.07 ; 3$ trials, $I^{2}=88 \%$, REM) plus SC was associated with shorter TFF as compared to that with SC alone. CE plus SC was associated with shorter TFF as compared to that with SC alone. However, no significant difference in TFF was observed between EA versus SA, and acupressure plus SC versus $\mathrm{SC}$ arms. The forest plot is presented in Figure 3.

\section{Secondary outcomes}

a. Time to first defecation: Five trials reported data pertaining to time to first defecation (TFD). Results of metaanalysis showed that treatment with acupuncture (MD: -10.16 h, $95 \%$ CI -19.01 to $-1.32,3$ trials, $I^{2}=77 \%$, REM) plus SC was associated with shorter TFR as compared to that with SC alone. Auriculotherapy plus SC and CE plus SC were associated with shorter TFD as compared to that with SC alone (Table 3). 
Table 1: Characteristics of the included studies.

\begin{tabular}{|c|c|c|c|c|c|c|}
\hline \multirow{2}{*}{ Reference } & \multirow{2}{*}{ Country } & \multirow{2}{*}{ Design } & \multirow{2}{*}{$\begin{array}{c}\text { No. of } \\
\text { Patients } \\
\text { (TG/CG) }\end{array}$} & \multirow{2}{*}{$\begin{array}{c}\text { Mean Age (Years) (TG/ } \\
\text { CG) }\end{array}$} & \multicolumn{2}{|c|}{ Surgery } \\
\hline & & & & & Type & Open/Laparoscopic \\
\hline Chen [21] & China & $\begin{array}{l}\text { two-arm } \\
\text { parallel } \\
\text { group } \\
\text { randomized } \\
\text { trial }\end{array}$ & $40(24 / 16)$ & $58 / 58$ & $\begin{array}{l}\text { colon cancer and } \\
\text { rectal cancer } \\
\text { surgery }\end{array}$ & laparoscope surgery \\
\hline Yang [31] & China & $\begin{array}{c}\text { two-arm } \\
\text { parallel } \\
\text { group } \\
\text { randomized } \\
\text { trial }\end{array}$ & $62(32 / 30)$ & $68.59 \pm 2.44 / 69.97 \pm 1.59$ & cholecystectomy & laparoscope surgery \\
\hline Kou [27] & China & $\begin{array}{c}\text { two-arm } \\
\text { parallel } \\
\text { group } \\
\text { randomized } \\
\text { trial }\end{array}$ & $40(20 / 20)$ & $58 \pm 21 / 58 \pm 11$ & gallstone surgery & open surgery \\
\hline Guo [23] & China & $\begin{array}{l}\text { three-arm } \\
\text { parallel } \\
\text { group } \\
\text { randomized } \\
\text { trial }\end{array}$ & $50(25 / 25)$ & NR & colorectal cancer & laparoscope surgery \\
\hline Cai [20] & China & $\begin{array}{l}\text { two-arm } \\
\text { parallel } \\
\text { group } \\
\text { randomized } \\
\text { trial }\end{array}$ & $78(39 / 39)$ & $57.3 / 56.4$ & cholecystectomy & open surgery \\
\hline Guo [24] & China & $\begin{array}{l}\text { two-arm } \\
\text { parallel } \\
\text { group } \\
\text { randomized } \\
\text { trial }\end{array}$ & $\begin{array}{c}90 \\
(30 / 30 / 30)\end{array}$ & NR & colorectal cancer & laparoscope surgery \\
\hline $\mathrm{Fu}[22]$ & China & $\begin{array}{l}\text { two-arm } \\
\text { parallel } \\
\text { group } \\
\text { randomized } \\
\text { trial }\end{array}$ & $60(30 / 30)$ & $48 / 47$ & $\begin{array}{c}\text { benign } \\
\text { gallbladder } \\
\text { polyps, gallstone }\end{array}$ & laparoscope surgery \\
\hline Qian [29] & China & $\begin{array}{l}\text { two-arm } \\
\text { parallel } \\
\text { group } \\
\text { randomized } \\
\text { trial }\end{array}$ & $62(31 / 31)$ & NR & $\begin{array}{l}\text { colorectal cancer } \\
\text { surgery }\end{array}$ & open surgery \\
\hline $\begin{array}{l}\text { Zhang ML } \\
\text { [32] }\end{array}$ & China & $\begin{array}{l}\text { three-arm } \\
\text { parallel } \\
\text { group } \\
\text { randomized } \\
\text { trial }\end{array}$ & $\begin{array}{c}136 \\
(46 / 45 / 45)\end{array}$ & $63 / 64 / 61$ & $\begin{array}{c}\text { gastrointestinal } \\
\text { surgery }\end{array}$ & open surgery \\
\hline Jin [25] & China & $\begin{array}{l}\text { two-arm } \\
\text { parallel } \\
\text { group } \\
\text { randomized } \\
\text { trial }\end{array}$ & $\begin{array}{c}216 \\
(108 / 108)\end{array}$ & $\begin{array}{c}42.42 \pm 12.58 / \\
43.48 \pm 11.38\end{array}$ & cholecystectomy & laparoscope surgery \\
\hline
\end{tabular}

Citation: Ling-shu W, Guannan L, Xuetong G, Jing L, Guang Y (2017) Acupoint Stimulation for Postoperative Ileus Following Gastrointestinal Surgery: A Systematic Review and Meta-Analysis of Randomized Controlled Trials. Int J Complement Alt Med 9(4): 00302. D0I: 10.15406/ijcam.2017.09.00302 


\begin{tabular}{|c|c|c|c|c|c|c|}
\hline $\begin{array}{c}\text { Zhang P } \\
\text { [33] }\end{array}$ & China & $\begin{array}{l}\text { two-arm } \\
\text { parallel } \\
\text { group } \\
\text { randomized } \\
\text { trial }\end{array}$ & $60(30 / 30)$ & NR & cholelithiasis & open surgery \\
\hline $\mathrm{Ng}$ [28] & China & $\begin{array}{l}\text { three-arm } \\
\text { parallel } \\
\text { group } \\
\text { randomized } \\
\text { trial }\end{array}$ & $\begin{array}{c}165 \\
(55 / 55 / 55)\end{array}$ & NR & colorectal cancer & laparoscopic surgery \\
\hline Sun [30] & China & $\begin{array}{c}\text { two-arm } \\
\text { parallel } \\
\text { group } \\
\text { randomized } \\
\text { trial }\end{array}$ & $\begin{array}{c}90 \\
(30 / 30 / 30)\end{array}$ & NR & $\begin{array}{c}\text { cholecystectomy } \\
\text { surgery }\end{array}$ & laparoscopic surgery \\
\hline Jin [26] & China & $\begin{array}{l}\text { two-arm } \\
\text { parallel } \\
\text { group } \\
\text { randomized } \\
\text { trial }\end{array}$ & $\begin{array}{c}150 \\
(75 / 75)\end{array}$ & $52.0 \pm 12.5 / 51.0 \pm 10.4$ & gallstone surgery & open surgery \\
\hline
\end{tabular}

Table 2: Detailed information on acupoint stimulation.

\begin{tabular}{|c|c|c|c|c|c|}
\hline \multirow{2}{*}{ Reference } & \multirow{2}{*}{$\begin{array}{c}\text { No. of } \\
\text { Patients } \\
\text { (TG/CG) }\end{array}$} & \multirow{2}{*}{ Age (Years) (TG/CG) } & \multicolumn{2}{|c|}{ Interventions } & \multirow[t]{2}{*}{ Outcomes } \\
\hline & & & TG & CG & \\
\hline Chen [21] & $40(24 / 16)$ & $58 / 58$ & $\begin{array}{l}\text { Acupressure at Zusanli (ST36) } \\
\text { and Hegu (LI4) bilaterally for } \\
20 \text { min at } 6 \text { h postoperatively } \\
\text { and thereafter repeated once } \\
\text { every } 4-6 \text { h until first flatus }\end{array}$ & $\begin{array}{l}\text { The same routine } \\
\text { postoperative care as } \\
\text { the intervention group, } \\
\text { excluding acupressure }\end{array}$ & TFF \\
\hline Yang [31] & $62(32 / 30)$ & $68.59 \pm 2.44 / 69.97 \pm 1.59$ & $\begin{array}{c}\text { Electroacupuncture at Zusanli } \\
\text { (ST36) and Sanyinjiao (SP6) } \\
\text { bilaterally } 4 \text { h postoperatively } \\
\text { for } 20 \text { min and thereafter } \\
\text { repeated every } 4 \mathrm{~h} \text { until first } \\
\text { flatus. }\end{array}$ & $\begin{array}{l}\text { The same routine } \\
\text { postoperative care as } \\
\text { the intervention } \\
\text { group, excluding EA }\end{array}$ & TFF \\
\hline Kou [27] & $40(20 / 20)$ & $58 \pm 21 / 58 \pm 11$ & $\begin{array}{l}\text { Acupuncture with filiform } \\
\text { needles ( } 0.3 \mathrm{~mm} \text { diameter, } \\
40 \mathrm{~mm} \text { length) on alternate } \\
\text { days bilaterally at Zusanli (ST } \\
\text { 36), Shangjuxu (ST 37), Xiajuxu } \\
\text { (ST 39), and Yanglingquan } \\
\text { (GB 34). On detection of } \\
\text { needling sensation, the doctor } \\
\text { performed } 20 \text { s of reinforcing- } \\
\text { reducing technique, followed } \\
\text { by needling manipulation } \\
\text { every 5-10 min with retention } \\
\text { for 20-30 min }\end{array}$ & $\begin{array}{l}\text { The same routine } \\
\text { postoperative care as } \\
\text { the intervention } \\
\text { group, excluding } \\
\text { Acupuncture }\end{array}$ & TFF,TFD \\
\hline
\end{tabular}

Citation: Ling-shu W, Guannan L, Xuetong G, Jing L, Guang Y (2017) Acupoint Stimulation for Postoperative Ileus Following Gastrointestinal Surgery: A Systematic Review and Meta-Analysis of Randomized Controlled Trials. Int J Complement Alt Med 9(4): 00302. D0I: 10.15406/ijcam.2017.09.00302 


\begin{tabular}{|c|c|c|c|c|c|}
\hline Guo [23] & $50(25 / 25)$ & NR & $\begin{array}{l}\text { Moxibustion, circling } \\
\text { moxibustion } 2 \text { minutes, then } \\
\text { bird-pecking moxibusion } 1 \\
\text { minute, and along the facial } \\
\text { nerves go and back } 2 \text { minutes } \\
\text { until the feeling disappear }\end{array}$ & $\begin{array}{l}\text { The same routine } \\
\text { postoperative care as } \\
\text { the intervention } \\
\text { group, excluding } \\
\text { moxibustion }\end{array}$ & TFF \\
\hline Cai [20] & $78(39 / 39)$ & $57.3 / 56.4$ & $\begin{array}{c}\text { Acupoint injection with } \\
\text { neostigmine methylsulfate } \\
1 \mathrm{~mL} \text { into Zusanli (ST36) } \\
\text { and Shangjuxu (ST37) at } 6 \mathrm{~h} \\
\text { postoperatively }\end{array}$ & $\begin{array}{l}\text { The same routine } \\
\text { postoperative care as } \\
\text { the intervention } \\
\text { group, excluding AI }\end{array}$ & TFF \\
\hline Guo [24] & $\begin{array}{c}90 \\
(30 / 30 / 30)\end{array}$ & NR & $\begin{array}{l}\text { Group } 1 \text { received moxibustion } \\
\text { at Zhongwan (CV12), Tianshu } \\
\text { (ST25), Shangjuxu (ST37), } \\
\text { and Zusanli (ST36), first } \\
\text { at } 6 \text { h postoperatively and } \\
\text { thereafter once daily until } \\
\text { recovery of bowel movement } \\
\text { (>3 bowel sounds per minute } \\
\text { on auscultation). Group } 2 \\
\text { received acupoint injection of } \\
\text { Vitamin B1 } 100 \text { mg bilaterally } \\
\text { into Zusanli bilaterally, first } 6 \mathrm{~h} \\
\text { postoperatively and thereafter } \\
\text { once daily until recovery of } \\
\text { bowel movement. }\end{array}$ & $\begin{array}{l}\text { The same routine } \\
\text { postoperative care as } \\
\text { the intervention } \\
\text { group, excluding } \\
\text { acupoint } \\
\text { Injection and } \\
\text { moxibustion }\end{array}$ & TFF \\
\hline $\mathrm{Fu}[22]$ & $60(30 / 30)$ & $48 / 47$ & $\begin{array}{l}\text { Auriculotherapy using Semen } \\
\text { Vaccariae administered at } \\
\mathrm{CO}_{4^{\prime}} \mathrm{CO}_{7}, \mathrm{CO}_{6} \text {, and } \mathrm{CO}_{17} \text { at } 4 \mathrm{~h} \\
\text { postoperatively and pressed } \\
\text { for } 5 \text { min until heat sensation } \\
\text { was elicited and thereafter } \\
\text { repeated every } 2 \text { hours until } \\
\text { the first flatus }\end{array}$ & $\begin{array}{l}\text { The same routine } \\
\text { postoperative care as } \\
\text { the intervention } \\
\text { group, excluding } \\
\text { acupoint Injection and } \\
\text { moxibustion }\end{array}$ & TFF \\
\hline Qian [29] & $62(31 / 31)$ & NR & $\begin{array}{c}\text { Catgut } 1.5 \mathrm{~cm} \text { implanted } \\
\text { into Zusanli (ST36) for } \\
\text { continuous stimulation at } 6 \mathrm{~h} \\
\text { postoperatively }\end{array}$ & $\begin{array}{l}\text { The same routine } \\
\text { postoperative care as } \\
\text { the intervention } \\
\text { group, excluding CE }\end{array}$ & $\begin{array}{l}\text { TFD, TFF, } \\
\text { LOS, TND }\end{array}$ \\
\hline $\begin{array}{c}\text { Zhang ML } \\
\text { [32] }\end{array}$ & $\begin{array}{c}136 \\
(46 / 45 / 45)\end{array}$ & $63 / 64 / 61$ & $\begin{array}{l}\text { Group } 1 \text { Acupoint injec- } \\
\text { tion with neostigmine me- } \\
\text { thylsulfate } 0.5 \text { mL into } \\
\text { Zusanli (ST36), every } 12 \\
\text { hours at a time; Group } 2 \\
\text { acupressure at Zusanli } \\
\text { (ST36) for } 10 \sim 15 \mathrm{~min} \text { each } \\
\text { time and thereafter repea- } \\
\text { ted once every } 4 \text { hours. }\end{array}$ & $\begin{array}{l}\text { The same routine } \\
\text { postoperative care as } \\
\text { the intervention } \\
\text { group, excluding } \\
\text { acupoint } \\
\text { Injection and } \\
\text { Acupressure }\end{array}$ & TFF \\
\hline
\end{tabular}

Citation: Ling-shu W, Guannan L, Xuetong G, Jing L, Guang Y (2017) Acupoint Stimulation for Postoperative Ileus Following Gastrointestinal Surgery: A Systematic Review and Meta-Analysis of Randomized Controlled Trials. Int J Complement Alt Med 9(4): 00302. DOI: 10.15406/ijcam.2017.09.00302 


\begin{tabular}{|c|c|c|c|c|c|}
\hline Jin [26] & $\begin{array}{c}216 \\
(108 / 108)\end{array}$ & $\begin{array}{c}42.42 \pm \\
12.58 / \\
43.48 \pm \\
11.38\end{array}$ & $\begin{array}{l}\text { Auricular acupuncture } \\
\text { using Semen Vaccariae } \\
\text { administered at CO7, CO6, } \\
\text { AT4, AT6a, and TF4 at } 6 \mathrm{~h} \\
\text { postoperatively and pres- } \\
\text { sed } 30-60 \text { s until heat sen- } \\
\text { sation was elicited; thereaf- } \\
\text { ter repeated every } 2 \text { hours } \\
\text { until the first flatus }\end{array}$ & $\begin{array}{l}\text { The same routine } \\
\text { postoperative care as } \\
\text { the intervention } \\
\text { group, excluding } \\
\text { auriculotherapy }\end{array}$ & $\begin{array}{l}\text { TFF, } \\
\text { TND }\end{array}$ \\
\hline $\begin{array}{c}\text { Zhang P } \\
\text { [33] }\end{array}$ & $60(30 / 30)$ & NR & $\begin{array}{l}\text { Auriculotherapy with } \\
\text { Semen Vaccariae fixed } \\
\text { on to auricular acupoints } \\
\text { of } \mathrm{CO}_{4}, \mathrm{CO}_{7}, \mathrm{CO}_{6}, \mathrm{CO}_{17} \\
\mathrm{CO}_{18} \text {, and } \mathrm{AH}_{6 \mathrm{a}} \text { with each } \\
\text { acupoint pressed for } \\
0.5 \text { min at } 6 \text { h postopera- } \\
\text { tively, then repeated every } \\
10 \text { min at the seventh } \\
\text { hour, and thereafter repe- } \\
\text { ated once every hour until } \\
\text { first flatus }\end{array}$ & $\begin{array}{l}\text { The same routine } \\
\text { postoperative care as } \\
\text { the intervention } \\
\text { group, excluding } \\
\text { auriculotherapy }\end{array}$ & TFD, TFF \\
\hline Ng [28] & $\begin{array}{c}165 \\
(55 / 55 / 55)\end{array}$ & NR & $\begin{array}{l}\text { Electroacpuncture applied } \\
\text { bilaterally at Zusan- } \\
\text { li (ST36), Sanyinjiao (SP6), } \\
\text { Hegu (LI4), and Zhigou } \\
\text { (TE6), at } 100 \mathrm{~Hz} \text { for } 20 \mathrm{~min} \text {, } \\
\text { with depth of insertion } \\
\sim 20 \mathrm{~mm} \text {. EA group unde- } \\
\text { rwent treatment from POD } \\
\text { 1, repeated for } 3 \text { days or } \\
\text { until TFF. }\end{array}$ & $\begin{array}{l}\text { The same routine } \\
\text { postoperative care as } \\
\text { the intervention } \\
\text { group, excluding EA. } \\
\text { Shorter needles } \\
\text { were inserted into } \\
\text { shallower areas away } \\
\text { from acupoints in the } \\
\text { SA group. SA group } \\
\text { underwent treatment } \\
\text { from POD 1, repeated } \\
\text { for } 3 \text { days or until TFF. }\end{array}$ & $\begin{array}{c}\text { TFD, } \\
\text { TND, LOS }\end{array}$ \\
\hline Sun [30] & $\begin{array}{c}90 \\
(30 / 30 / 30)\end{array}$ & NR & $\begin{array}{l}\text { Acupuncture with filiform } \\
\text { needles applied bilaterally } \\
\text { at Zusanli (ST36), Daimai } \\
\text { (GB26) for } 30 \text { min, then } \\
\text { repeated after } 6 \mathrm{~h} \text { on POD } 1\end{array}$ & $\begin{array}{l}\text { The same routine } \\
\text { postoperative care as } \\
\text { the intervention } \\
\text { group, excluding } \\
\text { acupuncture }\end{array}$ & TFD,TFF \\
\hline Jin [26] & $150(75 / 75)$ & $\begin{array}{l}52.0 \pm 12.5 / \\
51.0 \pm 10.4\end{array}$ & $\begin{array}{c}\text { Acupuncture with filiform } \\
\text { needles applied bilaterally } \\
\text { at Zusanli (ST36), Yanglin- } \\
\text { gquan (GB35), Shangjuxu } \\
\text { (ST37) for 25 30 min, once } \\
\text { daily }\end{array}$ & $\begin{array}{l}\text { The same routine } \\
\text { postoperative care as } \\
\text { the intervention } \\
\text { group, excluding } \\
\text { acupuncture }\end{array}$ & TFD,TFF \\
\hline
\end{tabular}

TFD: Time To Passage of First Flatus; TFFL: Time to First Defecation; LOS: Length Of Hospital Stay; TND: Time To Return To Normal Diet; TG: Treatment Group; CG: Control Group; NR: Not Reported;SC: Standard Care; EA: Electroacupuncture; SA: Sham Acpuncture; AI: Acupoint Injection; CE: Catgut Embedding At Acupoints 
Table 3: Effect estimates of the secondary outcomes for postoperative ileus.

\begin{tabular}{|c|c|c|c|}
\hline Interventions and Outcomes & Study ID & Sample Size (I/C) & Effect Estimates (95\% CI) \\
\hline \multicolumn{4}{|l|}{ Time to First Defecation } \\
\hline \multirow{3}{*}{ Acupuncture+SC vs. SC } & Jin [26] & $150(75 / 75)$ & MD: -10.16 [-19.01,-1.32] \\
\hline & Kou [27] & $40(20 / 20)$ & \\
\hline & Sun $[30]$ & $60(30 / 30)$ & $\mathrm{I}^{2}=77 \%, \mathrm{REM}$ \\
\hline Auriculotherapy+SC vs. SC & Zhang P [33] & $60(30 / 30)$ & MD: $-24.48[-30.52,-18.44]$ \\
\hline $\mathrm{CE}+\mathrm{SC}$ vs. SC & Qian [29] & $62(31 / 31)$ & MD: -12.86 [-21.34,-4.38] \\
\hline \multicolumn{4}{|l|}{ Length of Hospital Stay } \\
\hline $\mathrm{EA}+\mathrm{SC} v s . \mathrm{SC}$ & $\mathrm{Ng}[28]$ & $110(55 / 55)$ & MD: $-2.00[-3.40,-0.60]$ \\
\hline EA vs. SA & $\mathrm{Ng}[28]$ & $110(55 / 55)$ & MD: $-0.30[-1.03,0.43]$ \\
\hline $\mathrm{CE}+\mathrm{SC} v s . \mathrm{SC}$ & Qian [29] & $62(31 / 31)$ & MD: $-2.43[-5.24,0.38]$ \\
\hline \multicolumn{4}{|l|}{ Time to Return to Normal Diet } \\
\hline $\mathrm{EA}+\mathrm{SC} v s . \mathrm{SC}$ & $\mathrm{Ng}[28]$ & $110(55 / 55)$ & MD: $-19.20[-33.68,-4.72]$ \\
\hline EA vs. SA & $\mathrm{Ng}[28]$ & $110(55 / 55)$ & MD: $-2.40[-11.03,6.23]$ \\
\hline Auriculotherapy+SC vs. SC & $\operatorname{Jin}[25]$ & $216(108 / 108)$ & MD: $-6.48[-6.79,-6.17]$ \\
\hline $\mathrm{CE}+\mathrm{SC} v s \mathrm{SC}$ & Qian [29] & $62(31 / 31)$ & MD: -13.44 [-36.54,9.66] \\
\hline
\end{tabular}

REM: Random Effects Model; MD: Mean Difference; SC: Standard Care; EA: Electroacupuncture; SA: Sham Acupuncture; CE: Catgut Embedding At Acupoints; I/C: Intervention/Control

b. Length of hospital stay: Data pertaining to LOS were available only for two trials. Treatment with EA plus SC was associated with shorter LOS as compared to that with SC alone. However, no significant difference was observed in this respect between EA and SA or between CE plus SC and SC groups (Table $3)$.

c. Time to return to normal diet: Data pertaining to time to return to normal diet (TND) was available only for three trials. No significant difference was observed with respect to TND between CE plus SC and SC groups or between EA and SA groups. However, treatment with auriculotherapy plus SC and EA plus SC was associated with significantly shorter TND as compared to that with SC alone (Table 3).

d. Mortality: None of the trials reported data on mortality.

e. Adverse events: None of the trials reported data on adverse events.

\section{Discussion}

\section{Main findings}

A total of 14 studies with a combined study population of 1299 patients were included in this review. The selected studies investigated the role of acupoint stimulation in patients who developed postoperative ileus after cholecystectomy or surgery for colorectal cancer (both laparoscopic and open surgery). In most of the studies, acupoint stimulation was associated with significant shortening of TFD and TFF as compared to that associated with standard care.

\section{Limitation}

Firstly, the included studies showed significant clinical heterogeneity with respect to age and sex of patients, preoperative preparation, surgical anesthesia, postoperative analgesia, intraoperative bleeding, routine postoperative care, 
background of acupuncturists, and precise description of the control group. Secondly, protocols for acupoint stimulation were not defined with respect to time of initiation, number, and depth of needle insertion, number of treatment sessions, frequency and duration of treatment sessions, and details of other interventions administered to the acupoint group. Moreover, adverse events were not reported from any of the studies. Therefore, the safety aspects of this treatment in patients with postoperative ileus could not be determined. Thirdly, in most studies, data on TFF was based on patient self-reporting, the reliability of which is open to question.

\begin{tabular}{|c|c|c|c|c|c|c|c|}
\hline & 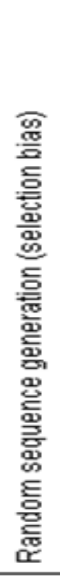 & 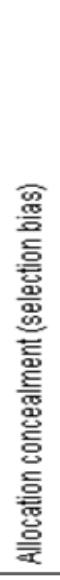 & 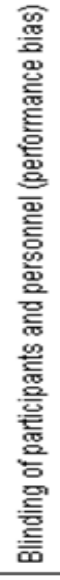 & 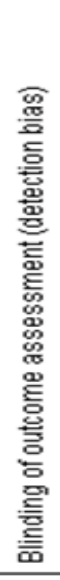 & 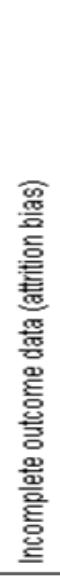 & 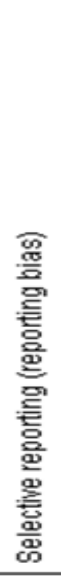 & 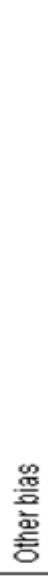 \\
\hline Cai 2011 & $?$ & $?$ & $?$ & $?$ & + & $?$ & $?$ \\
\hline Chen 2008 & $?$ & $?$ & $?$ & $?$ & + & $?$ & $?$ \\
\hline Fu 2011 & $?$ & $?$ & $?$ & $?$ & + & $?$ & $?$ \\
\hline Guo 2010 & $?$ & $?$ & $?$ & $?$ & + & $?$ & $?$ \\
\hline Guo 2011 & $?$ & $?$ & $?$ & $?$ & + & $?$ & $?$ \\
\hline $\operatorname{Jin} 2012$ & $\oplus$ & $?$ & $?$ & $?$ & + & $?$ & $?$ \\
\hline Jin 2016 & 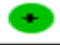 & $?$ & $?$ & $?$ & + & $?$ & $?$ \\
\hline Kou 2011 & $?$ & $?$ & $?$ & $?$ & $\oplus$ & $?$ & $?$ \\
\hline $\mathrm{Ng} 2013$ & $?$ & + & + & $\oplus$ & + & + & + \\
\hline Qian 2011 & $?$ & $?$ & $?$ & $\leftarrow$ & + & $?$ & $?$ \\
\hline Sun 2015 & $?$ & $?$ & $?$ & $?$ & + & $?$ & $?$ \\
\hline Yang 2008 & $?$ & $?$ & $?$ & $?$ & $\oplus$ & $?$ & $?$ \\
\hline Zhang ML 2012 & $?$ & $?$ & $?$ & $?$ & + & $?$ & $?$ \\
\hline Zhang P 2012 & + & $?$ & $?$ & $?$ & + & $?$ & $?$ \\
\hline
\end{tabular}

Figure 2: Summary of the risk of bias.

\section{Comparison with other Reviews}

Wang et al. [35] reviewed the use of acupoint injection with different medicines for prevention of postoperative ileus. In their meta-analysis, acupoint injection of neostigmine, vitamin B1, or metoclopramide compared to usual care showed a beneficial effect on the time to recovery of bowel sounds, TFD or TFF. The outcome was similar to that used in the present study. However, due to poor methodological quality, definitive conclusions could not be derived [34].

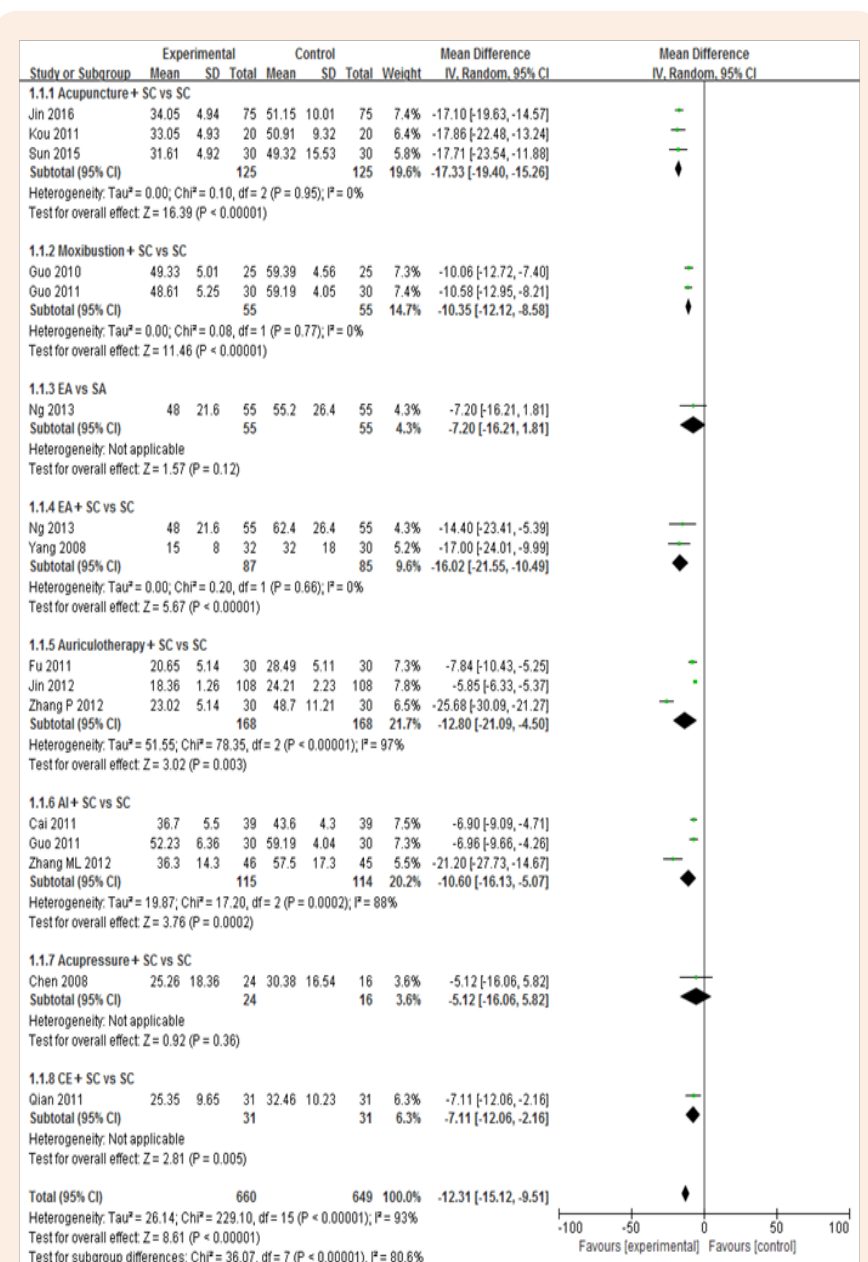

Figure 3: Forest plot of time to passage of first flatus.

SC: standard Care; EA: Electroacupuncture; SA: Sham acpuncture; AI: Acupoint injection; CE: Catgut Embedding at Acupoints

\section{Conclusion}

The evidences included in this review have a lot of unclear risk of bias because of lack of sufficient information. Moreover, none of the studies provided information on adverse events related to acupoint stimulation. Therefore, this treatment for patients with postoperative ileus needs to be further studied in terms of efficacy and safety.

High-quality randomized controlled trials of acupoint stimulation for treatment of postoperative ileus are required. These should employ adequate sample size, rigorous randomization methods and appropriate blinding techniques. 
Moreover, in this modality of treatment, blinding of assessors and statisticians would be more realistically feasible.

\section{Funding Source}

This research did not receive any specific grant from funding agencies in the public, commercial, or not-for-profit sectors.

\section{Authors Contribution}

LSW: protocol development, literature search, quality assessment of trials, development of final review.

XTG: literature search, assessment of trials, data extraction, data entry.

GN L: development of final review.

JL: literature search, assessment of trials, data extraction.

GY: data input.

\section{Conflict of Interest}

All authors declare that they have no conflict of interests.

\section{Acknowledgements}

Special thanks to Yi Li from Heilongjiang University of Chinese Medicine for his advice on the inclusion criteria.

\section{References}

1. Vather R, Trivedi S, Bissett I (2013) Defining postoperative ileus: results of a systematic review and global survey. J Gastrointest Surg 17(5): 962-972.

2. Iyer S, Saunders WB, Stemkowski S (2009) Economic burden of postoperative ileus associated with colectomy in the United States, J Manag Care Pharm 15(6): 485-494.

3. Doorly MG, Senagore AJ (2012) Pathogenesis and clinical and economic consequences of postoperative ileus. Surg Clin North Am 9 (2): $259-272$

4. Leslie B (2005) Alvimopan for the management of postoperative ileus. Ann Pharmacother 39(9): 502-510.

5. Sanger GJ, Holzer P (2005) Endogenous opioids and the gastrointestinal tract. Semin Colon Rectal Surg 16(4): 197-199.

6. Behm B, Stollman N (2003) Postoperative ileus: etiologies and interventions. Clin Gastroenterol Hepatol 1(2): 71-80.

7. Berend KR, Lombardi AV Jr, Mallory TH, Dodds KL, Adams JB (2004) Ileus following total hip or knee arthroplasty is associated with increased risk of deep venous thrombosis and pulmonary embolism. J Arthroplasty 19 (7 Suppl 2): 82-86.

8. Balestrini JL, Tsuchida D, Fukuda H, Pappas TN, Takahashi T (2005) Acupuncture accelerates delayed gastrointestinal transit after abdominal surgery in conscious rats. Scand J Gastroenterol 40(6): 734-735.

9. Liodden I, Howley M, Grimsgaard AS, Fønnebø VM, Borud EK, et al. (2011) Perioperative acupuncture and postoperative acupressure can prevent postoperative vomiting following paediatric tonsillectomy or adenoidectomy: a pragmatic randomised controlled trial. Acupunct Med 29(1): 9-15.
10. Yin J, Chen JD (2010) Gastrointestinal motility disorders and acupuncture. Auton Neurosci. 157 (1-2) 31-37.

11. Zou D, Chen WH, Iwakiri K, Rigda R, Tippett M, et al. (2005) Inhibition of transient lower esophogeal sphincter relaxations by electrical acupoint stimulation. Am J Physiol Gastrointest Liver Physiol 289(2): G197-G201.

12. Iwa M, Matsushima M, Nakade Y, Pappas TN, Fujimiya M, et al. (2006) Electroacupuncture at ST-36 accelerates colonic motility and transit in freely moving conscious rats. Am J Physiol Gastrointest Liver Physiol 209(2): G285-G292.

13. Du MH, Luo HM, Tian YJ, Zhang LJ, Zhao ZK, et al. (2015) Electroacupuncture ST36 prevents postoperative intra-abdominal adhesions formation. J Surg Res 195(1): 89-98.

14. Jiang H (2003) 105 cases of gastrointestinal dysfunction syndrome after operation with acupuncture. LiShiZhen Medicine and Materia Medica Research 14(6): 364-365.

15. Qin J (2002) 36 cases of postoperative paralytic ileus treated with electro-acupuncture. Zhejiang Clinical Medical Journal 4(7): 537.

16. Tian YJ, Wang L, Geng SJ, Bao CM, Jin F, et al. (2008) Electroacupuncture $\mathrm{Zu}$ Sanli for adhesion after operation in rat. Infection Inflammation Repair 9: 153-156.

17. Li H, Wu JW, Chen SJ, Liu JW, J.W. Zhang, Acupuncture for mucosa ultrastructure of adhesive ileus in rat. Liaoning Journal of Traditional Chinese Medicine 35(7): 1094-1096.

18. Liu Y, Li P (2015) Acupuncture on serum TNF- $\alpha$ and IL-6 and small intestinal transit rate in rats with incomplete intestinal obstruction. World Chinese Journal of Digestology 2 (24): 3894-3898.

19. Meng ZQ Garcia MK, Chiang JS, Peng HT, Shi YQ, et al. (2010) Electro-acupuncture to prevent prolonged postoperative ileus: A randomized clinical trial. World J Gastroenterol 16(1): 104-111.

20. Min C (2011) Effects of acupoint injection on enterocinesia in patients with open abdominal gallbladder surgery. Shanghai Nursing 11(3): 27-29.

21. YL (2008) Point massage for abdominal distention of laparoscopic colorectal cancer. Journal of Emergency in Traditional Chinese Medicine 8(31): 31 .

22. [22]N. Fu, X.F. Wang, J.G. Cao, Acupressure bean on ear for postoperative ileus in patients with laparoscopic cholecystectomy, Acta Chinese Medicine and Pharmacology. 39 (1) (2011) 68-69.

23. Guo LX, Ru HF, Fang R, He YJ, Zeng XY (2010) Effects of temperature sensitive acupoint acupuncture and moxibustion on the recovery of enterokinesia after intestinal Iaparoscopic operations. J Nurs Sci 25(16): 32-33.

24. Guo LX (2011) Comparison on effect of different methods of promoting intestinal peristalsis recovery for patients after accepting laparoscopic intestinal operation, Chinese Nursing Research 25(8): 2078-2079.

25. Jin HM, Lu JY, Zhu HJ (2012) Acupressure bean on ear for intestinal peristalsis recovery after laparoscopic cholecystectomy. Jorunal of Emergency in Traditional Chinese Medicine 21(2): 37-38.

26. JinH (2016) The clincal observation of puncturing the lower Hesea points in treatment of functional gastrointestinal disorder after gallstone removal surgery. Journal of New Chinese Medicine 48(10): 73-74. 
27. Kou XR, Sun LM, Guo N, Li P (2011) Clinical observation on acupuncture treatment of functional gastrointestinal disorder after gallstone surgery. Journal of Acupuncture and Tuina Science 9(3): 182-194.

28. Ng SS, Leung WW, Mak TW, Hon SS, Li JC, et al. (2013) Electroacupuncture Reduces Duration of Postoperative Ileus AfterLaparoscopic Surgery for Colorectal Cancer. Gastroenterology 144(2): 307-313.

29. Qian GZ (2011) Catgut Implantation at Zusanli Acupoint to Promote Gastrointestinal Rehabilitation after Colorectal Cancer Operation, Master's thesis, Guangzhou, China.

30. Sun GZ, Yang XW (2015) Acupuncture at Daimai and Zusanli for gastrointestinal recovery of elder patients after laparoscopic cholecystectomy. Journal of Clinical Acupuncture and Moxibustion 31(9): 23-25.
31. Yang HJ, Liu JF (2008) Electroacupuncture to promote passage of gas after laparoscopic cholecystectomy in the elderly. Medical Recapitulate 14(21): 3347-3348.

32. Zhang ML, Lv LY, Liu HS (2012) Observation of postoperative abdominal distention after acupoint injection of neostigmine. Chinese Journal of Practical Medicine 39(14): 94-95.

33. Zhang P, Wang YL, Li JT, Wang WR (2012) Ear acupressure to improve gastrointestinal function following surgery. Nursing Practice and Research 9(22): 37-38.

34. Wang M, Gao YH, Xu J, Chi Y, Wei XB (2015) Zusanli (ST36) acupoint injection for preventing postoperative ileus:A systematic review and meta-analysis of randomized clinical trials. Complement Ther Med 23(3): 469-483. 